\title{
The role of supervisory neglect in childhood injury
}

\section{Debbie Scott, Daryl Higgins \& Richard Franklin}

Children are vulnerable to different types of injury depending on their stage of growth and development. Children will also need varying degrees of supervision depending on their exposure to a range of risk and protective factors. This paper explores the theoretical understandings of supervisory neglect and how these understandings might assist in delivering practical responses using a public health approach to child protection.

\section{KEY MESSAGES}

- There is no universally accepted, all encompassing definition of the concept of "neglect", and consideration of supervisory neglect suggests that there is no "one size fits all" definition.

- Supervision can be a complex, resource-intensive activity when undertaken at its maximum effectiveness-understanding and evaluating what comprises "good enough parenting" remains subjective and is difficult to evaluate.

- Identification of neglect should pay heed to parental competence and/or caregiver capability, cultural context, child personality and level of maturity, and environmental risk factors.

- The need to forecast where future harm may arise from a lack of appropriate supervision is paramount.

- Impoverished families living in "poor" neighbourhoods may be unable to provide adequate nutrition, medical care or education for their children not because of a lack of recognition of the child's needs or a want to do so, but because of a lack of access to resources.

- Exposure to one type of harm (such as neglect) increases the risk of exposure to other forms of harm (such as physical or sexual abuse). In a child protection context, if children suffer a number of injuries this may serve as a warning that there are other issues of a potentially neglectful nature. 


\section{Child injury}

Injury is the leading cause of death in Australians 1-44 years of age (McClure, Stevenson, \& McEvoy, 2004). Transport-related injury, drowning, and assault/homicide were the three leading causes of injury-related deaths in Australian children between 2004 and 2006 (AIHW, 2009). Children are particularly vulnerable to different types of injury depending on their stage of growth and development. This vulnerability is dependent on a combination of the child's developmental stage, exposure to environmental risk factors and the presence of protective factors (Towner \& Dowswell, 2002).

Due to the diverse nature of injury in the population, prevention programs are mainly targeted at similar types of injury or circumstances in specific population groups. Examples of such targeted programs include preventing car crashes in newly licensed young drivers or educating beach goers to swim between the flags.

\section{Role of intent}

The International Classification of Diseases (ICD) (World Health Organization, 1992) is used to apply a statistical classification to injury causes. The role of intent in the causal chain of injury is classed as intentional, unintentional or undetermined. Undetermined intent is used to capture those injuries that cannot be clearly assigned a category of unintentional or intentional injury, such as the teen who dies after taking a large number of sleeping tablets after a fight with a parent, but has not expressed any suicidal intent and has not left a note. It may be unclear whether the intention is to simply be able to sleep, to express-or draw attention to-their distress, or indeed to die. Unintentional injury has, in the past been classed as "accidental", however injury prevention practitioners tend not to use such terminology as it imparts a fatalistic or non-preventable perspective (Langley, 1986). An example of unintentional injury is a child breaking an arm due to a fall while skateboarding, or a young rugby player who sprains an ankle while tackling another player. Intentional injuries are those injuries where the intent is to cause harm. These include assaults such as a father who punches a teen with the intent of teaching him a lesson and at the most serious includes homicide. Intentional injury can also be self-directed, as in the adolescent who causes disfigurement by cutting her arms and legs; or at the most severe, suicide where the victim has clearly expressed an intent to die.

Researchers are now acknowledging that the division between unintentional and maltreatmentrelated injuries is perhaps an artificial one from a prevention perspective. Peterson and Brown (1994) compared the likelihood of injuries being either unintentional or maltreatment-related, and found that the following characteristics were not reliable predictors of an injury classified as "unintentional" or "maltreatment-related": low socio-economic status backgrounds; chaotic, noisy or unintentional families; crowded home environments; families that were highly mobile or had limited access to support services; or parents with histories of substance abuse or mental health issues. In a recent study exploring maltreated children identified in health data sets, Schnitzer, Slusher, Kruse, and Tarleton (2011) found that burns, poisonings and drowning-related injury in children under 4 years of age were frequently associated with maltreatment. If not in terms of inflicted injury then as injuries that were, for the most part, preventable and so occurred in absence of appropriate protective factors, particularly supervision.

\section{Prevention of childhood injury}

Theoretically, all childhood injury is preventable. Normally an injury occurs as a result of a chain of events, where effective intervention at any point would minimise the consequences and may prevent the injury event altogether. For injury prevention programs to be effective they often require a range of strategies-including community empowerment, environmental modification, education 
(including knowledge and skill development), behaviour change, engineering solutions, legislation, and economic incentives (Liller, 2001). If all these strategies were ideally and concurrently applied the end result would theoretically be no childhood injury. However, these are seldom implemented at the same time. For example, a secure pool fence will restrict a toddler's access to a pool, however, if an older sibling or adult leaves the gate open, the gate is not securely fastened to supporting structures, the gate is broken or the toddler has learned how to open the gate he/she may still gain access to the pool and a drowning may occur. In an ideal world, a range of secondary solutions would be implemented as "failsafe" measures, for example, a self-closing and latching mechanism on the gate to ensure it cannot unintentionally be left open. Further a standard could be enacted to ensure all gates are fitted and certified by trained professionals and the gate has a regular inspection program to ensure its functionality. However, even with all preventive measures in place, if a toddler pushes a pot plant up to the fence and climbs over, even the most rigorous inspection program will not be successful. Often, therefore, the failsafe mechanism in prevention of childhood injury is supervision.

\section{Supervision}

Supervision is a commonly used term to describe the process of a person having responsibility for another person; it is applicable in a range of contexts from workplaces to the beach and is often seen as a strategy for the prevention of childhood injuries (Saluja et al., 2004).

In theory, if adequate supervision is provided, it is unlikely that a toddler will drown. However, while supervision may be seen as the panacea for the prevention of childhood injuries, competing demands for supervisors' attention mean that it is not possible to supervise a child all of the time. Additionally, children are injured while being supervised and not all children who are inadequately supervised are injured. Ideally, in situations where a supervisor's attention is momentarily diverted, other injury prevention methods intervene in the chain of events to prevent the injury. It should also be noted that supervision requirements vary according to circumstances. Logic suggests that environments with higher risks of injury will require increased supervision, such as around a body of water or fire. A child's propensity for adventure (risk taking) means that some children are more likely to place themselves at risk, therefore different children in the same environment will require different levels of supervision. However, it is clear that there are circumstances when appropriate supervision is the only solution that will keep a child safe, for example when bathing.

The description, identification and measurement of adequate supervision is difficult as there are many components to supervision. Initially, a supervisor must have the knowledge and understanding to recognise the risk and then have the capacity to intervene, preventing the injury event from occurring (Morrongiello, 2005). In addition, attention, proximity and continuity (Saluja et al., 2004) as well as preparedness (Budeja \& Franklin, in press) contribute to effective supervision. Supervision can be a complex, resource intensive activity when undertaken at its maximum effectiveness. Underlying this, and moderating the level of required supervision, is the environment or location; the activity and personality of the child; the number of children being supervised at any given time; and other competing demands on the supervisor.

\section{Neglect}

In Australia in 2010-11 neglect formed 29\% of all substantiated reports of harm to children nationally, accounting for anywhere from $8 \%$ in Victoria to $49 \%$ in the Northern Territory (Australian Institute of Health and Welfare [AIHW], 2012). Despite forming a large proportion of substantiated maltreatment, Dubowitz (1994) suggested that neglect is the least well-researched form of maltreatment and that this lack of research was due to the lack of a clear definition of the phenomenon.

The focus on neglect in statutory child protection systems is "new" in one sense. The modern statutory child protection systems were set up in the 1970s and 80s to respond to severe cases of 
harm-typically, these were seen as events such as physical abuse or sexual abuse. There was an increased focus on neglect in the 1990s, based on social science research showing the potential for neglect to have severe impacts on children's development. Now the category of neglect typically forms the largest proportion of all substantiations of harm to children across each state and territory (with the exception of Victoria, where the largest category of harm is "emotional"). The Northern Territory stands out in particular, with neglect making up approximately half of all substantiations (AIHW, 2012).

However, neglect has a long history in the antecedents to the formal statutory child protection system in Australia. The early child rescue movement of the late 19th and early 20th century was primarily focused on "rescuing" children from neglect by "morally corrupt and lazy" parents (Bromfield \& Holzer, 2008; Lamont \& Bromfield, 2010). One of the reasons why the focus on neglect has re-emerged on the child welfare agenda is the understanding of the chronic nature of many forms of maltreatmentparticularly neglect and emotional abuse. Many families in the statutory child protection systems across Australia have been subject to multiple notifications (chronic maltreatment), sometimes for several different types of child maltreatment (multi-type maltreatment). Child protection authorities now recognise the cumulative harm from ongoing exposure to lower levels of abuse or neglect, even if a single event does not satisfy the criteria for statutory intervention (Bromfield, Gillingham, \& Higgins, 2007; Higgins \& Katz, 2008). Research has also shown that exposure to one type of harm (such as neglect) increases the risk of exposure to other forms of harm (such as physical or sexual abuse), and the experience of multi-type maltreatment is common and associated with poorer outcomes for children experiencing one type of harm alone (Higgins, 2004).

There are a number of definitions of neglect, but generally speaking neglect is understood to be a failure, on the part of a caregiver, to provide for the physical, psychological, developmental and medical wellbeing of a child. However, unlike other forms of child maltreatment, there is no universally accepted, all-encompassing definition of the concept of neglect. Sexual abuse and physical abuse are clearly understood to be abuse regardless of the context, or the characteristics of the perpetrator or child. Physical and sexual abuse are acts of commission, a behaviour or incident can be clearly identified and described, neglect, on the other hand is the result of an omission of behaviour, a much more difficult concept to quantify and more likely to be influenced

Impoverished families may be unable to provide adequate nutrition, medical care or education for their children not because of a lack of recognition of the child's needs or a want to do so; but because of a lack of access to resources to enable that. by risk factors that a parent or caregiver may or may not have direct influence over. Poverty is one such risk factor. Impoverished families may be unable to provide adequate nutrition, medical care or education for their children not because of a lack of recognition of the child's needs or a want to do so; but because of a lack of access to resources to enable that. Poor families also may face additional challenges in supervising children due to their lack of access to resources and safe products and the distraction of stresses and anxiety due to the concerns of everyday living.

Table 1 summarises some of the critical differences between different types of maltreatment in terms of how they are measured or identified, and the role of the child protection and criminal or justice system in each. Sexual abuse is the most easily classified type of abuse once it has been established that a particular behaviour has taken place: the child was either sexually abused or not and the child protection focus is whether or not a parent or caregiver will protect, supervise and respond appropriately to ensure the safety of the child. If a child is sexually abused a criminological focus results in charges and convictions, there is no regard for extenuating circumstances or the severity of the impact of the abuse on the child. Moving down the table there is an increasing complexity both in terms of identifying when a situation constitutes abuse and whether it warrants a child protection response. Physical abuse depends on whether or not an injury is inflicted but the severity (serious harm) and chronicity of that abuse may also be taken into consideration. For many types of maltreatment, charges and convictions of perpetrators are uncommon. In addition to the 
Table 1. Maltreatment type by measurement dimension, child protection focus and criminological focus

\begin{tabular}{|c|c|c|c|}
\hline Maltreatment type & Measurement dimension & Child protection focus & Criminological focus \\
\hline Sexual abuse & Binary (yes/no) & $\begin{array}{l}\text { Parental failure to protect, } \\
\text { supervise and respond } \\
\text { appropriately }\end{array}$ & $\begin{array}{l}\text { Does not consider } \\
\text { extenuating circumstances } \\
\text { Focuses on age and consent } \\
\text { issues }\end{array}$ \\
\hline Physical abuse & $\begin{array}{l}\text { Binary (yes/no) but severity is } \\
\text { also considered }\end{array}$ & $\begin{array}{l}\text { Defined by the act of harming } \\
\text { inflicting serious harm }\end{array}$ & $\begin{array}{l}\text { Prosecution for assault in } \\
\text { severe cases }\end{array}$ \\
\hline Exposure to domestic violence & $\begin{array}{l}\text { Binary (yes/no) but also severity } \\
\text { is considered }\end{array}$ & $\begin{array}{l}\text { Defined by consideration of } \\
\text { causing serious harm now or in } \\
\text { the future }\end{array}$ & Only if child is assaulted \\
\hline $\begin{array}{l}\text { Psychological or emotional } \\
\text { abuse }\end{array}$ & $\begin{array}{l}\text { Continuum of severity and } \\
\text { chronicity }\end{array}$ & $\begin{array}{l}\text { Defined by consideration of } \\
\text { causing serious harm now or in } \\
\text { the future }\end{array}$ & No \\
\hline Physical neglect & $\begin{array}{l}\text { Continuum of severity and } \\
\text { chronicity }\end{array}$ & $\begin{array}{l}\text { Defined by consideration of } \\
\text { causing serious harm now or in } \\
\text { the future }\end{array}$ & $\begin{array}{l}\text { Rarely in cases of severe } \\
\text { neglect }\end{array}$ \\
\hline $\begin{array}{l}\text { Psychological or emotional } \\
\text { neglect }\end{array}$ & $\begin{array}{l}\text { Continuum of severity and } \\
\text { chronicity }\end{array}$ & $\begin{array}{l}\text { Defined by consideration of } \\
\text { causing serious harm now or in } \\
\text { the future }\end{array}$ & No \\
\hline Supervisory neglect & $\begin{array}{l}\text { Continuum of severity and } \\
\text { chronicity }\end{array}$ & $\begin{array}{l}\text { Defined by consideration of } \\
\text { causing serious harm now or in } \\
\text { the future }\end{array}$ & $\begin{array}{l}\text { Rarely in cases of severe } \\
\text { neglect }\end{array}$ \\
\hline
\end{tabular}

complexity of measurement definition, with a continuum of severity considered in the definition and the child protection response for exposure to domestic violence, emotional abuse and neglect, the child protection response must also consideration of whether the harm is likely to occur in the future.

Strauss and Kantor (2005) provided a definition of neglect for research purposes as:

Behaviour by a caregiver that constitutes a failure to act in ways that are presumed by the culture of a society to be necessary to meet the developmental needs of a child and which are the responsibility of the caregiver to provide. (p. 20)

This definition assumes cultural, behavioural, and responsibility factors play a role in the definition. The Queensland Child Safety Services described the occurrence of neglect as "when a child's basic necessities of life are not met, and their health and development are affected" (Queensland Department of Communities, 2011, para 11). Dubowitz, Black, Starr, and Zuravin (1993) pointed out that there can be no clear definition of neglect without a societal understanding of what constitutes adequate care and advocates for a shift from considering neglect to be a construct of parental culpability to that of a shared responsibility between parents, families, communities, and society. They suggested that any assessment for neglect must consider the frequency and chronicity of the behaviour and the likelihood and severity of potential and actual harm, the maturity of the child. Further, this must all be considered in the ecological context of poverty and parental or caregiving capability.

As can be seen in the conceptualisation of neglect in these definitions, understanding and evaluating what comprises "good enough parenting" remains subjective and difficult to evaluate (Budd, 2001), particularly if the evaluation is complicated by socio-economic and/or cultural factors. Ultimately, identification remains a subjective decision with parental competence, cultural context, child 
personality, and environmental risk all playing a role in its identification-despite arguments that identification of maltreatment must remain an objective decision (Higgins, 1998).

To further complicate the definitional issue, child protection authorities use the concept of harm, and some, serious harm, as a threshold for substantiating the actual or likely consequences of neglect, despite a lack of a concrete, universal definition of what serious harm looks like. It is possible for one incident of neglectful behaviour to result in the death of a child. Conversely, a child who is frequently left unattended may not come to any harm. As described by Straus and Kantor (2005), harm is not considered in definitions of other forms of maltreatment, sex with a child is sexual abuse by definition, the amount of harm or the ability to measure the harm caused by the act is considered in isolation (Strauss \& Kantor, 2005).

\section{Supervisory neglect}

Supervisory neglect is a form of neglect whereby inadequate supervision leads to or has the potential to lead to harm to the child. The difficulty in adequately defining supervisory neglect is compounded by a lack of clarity of what constitutes adequate supervision in a given situation, combined with the lack of clarity in defining neglect.

Hymel and the Committee on Child Abuse and Neglect (2006) suggested that an assessment of supervisory neglect should include:

- the ability of the child to exercise appropriate decision making;

- their knowledge of emergency phone numbers;

- accessibility to a caregiver;

the child's age;

- what the child's activities were while unsupervised;

whether or not the child is comfortable with the lack of supervision;

- child abilities;

- length of time and time of day the child is unattended;

- caregiver reasoning and understanding of the situation;

the potential danger to the child in an environmental context;

- previous incidents of neglect or abuse;

- the ability of the caregiver to care for the child; and

- how many other children the caregiver is responsible for.

This assessment involves consideration of the capabilities of the parent or caregiver and the child, the relationship shared by the child and the parent and how the lack of supervision poses a risk to the child (Budd, 2001).

In determining the risk, consideration must be given to available resources for the child in the absence of the parent. For example, a child who is left alone after school for a short time while a parent is on their way home from work may be quite comfortable with the situation because of the proximity of neighbours and while they may be alone in the home, the parent may have established a system of having the child monitored by the neighbour to ensure their safety until the parent arrives home. A parent in such circumstances may be left with a decision of being home to supervise the children or losing their job and being unable to house (pay rent) or feed the child, neither being the ideal situation.

The above example also calls into play issues of socio-economic status and the resources available to impoverished families and those families living in "poor" neighbourhoods. In such circumstances, there may be restricted availability to childcare or the cost of formal child care may be beyond 
the resources of a family, thereby necessitating children being left without formal supervision for periods of time. Similarly, in homes where financial resources are limited and/or the home is rental accommodation, the ability to modify the physical environment or purchase safety equipment, such as bicycle helmets or gates to restrict access to stairs, may be limited. Any definition of neglect therefore, must account for parental willingness to provide as safe an environment as possible, given available resources.

Intervention by child protection authorities to deem parenting behaviour as abusive or neglectful does not occur on an arbitrary basis but is based on legal definitions. Each state or jurisdiction has a legislation to describe the point at which state intervention can occur and a child is considered to be in need of protection (Holzer \& Bromfield, 2010). From a child protection perspective the parental intent or willingness to "do the right thing" is considered in any substantiation of maltreatment. The ability of any individual to adequately supervise children will depend on the age of the child, the personality of the child, the number of children for whom the supervisor is responsible, the activity of the child at the time and even whether or not the supervising adult is affected by alcohol or other substances. For example, supervising three quiet toddlers calmly watching TV in a family room requires quite different capabilities to supervising six active toddlers in the same family room or the same three children on a crowded beach.

Child protection authorities would also consider if adult caregivers knowingly place children at risk, for example, an alcohol affected parent who does not hold a current drivers licence, putting children into an unregistered car where they are not appropriately restrained and then proceeding to drive in a reckless manner could be considered supervisory neglect.

Another important consideration of whether or not a case of supervisory neglect reaches a threshold for intervention is the chronicity of the problem or clear patterns of behaviour that expose risk for the child. A parent may not see the risk in a situation (e.g., leaving young children alone in a car while they go into a shop for a short time) or they may be incapable of supervision for frequent periods of time (e.g., due to alcohol or drug addiction). In these circumstances a pattern of behaviour becomes apparent which frequently exposes the child to risk of serious harm.

\section{Examples of how situations influence the view/response of child protection authorities}

A common scenario in childhood injury is where a number of adults are monitoring children in a social situation, like that which may occur where a group of families gather for a barbeque and the children are swimming in a backyard pool. It is not uncommon for children to drown in this setting as each parent assume the other is watching a child. Further, there are a number of other adults near the pool, so the assumption is made that the pool—and any children in the pool—are being well monitored. The adults are busy socialising, perhaps sharing a drink or two and suddenly someone notices a child at the bottom of the pool, or missing. Quite likely, both parents are of the belief that the child is safe in the care of the other parent. While this could be considered to fall within a formal definition of supervisory neglect because the child is in a situation recognised to require close supervision and neither parent is providing adequate supervision, from a child protection perspective it is unlikely to meet the threshold of neglect as both parents are willing to protect the child from harm. A similar judgement may not be forthcoming if a parent were to be home alone with a young toddler and under the effects of recreational drugs, put them in a bathtub and then leave them unattended. Clearly the parental willingness to protect the child could be viewed as inadequate, and even more so were this to be part of a pattern of behaviours where the child was frequently put at risk because of the parent's drug habits. 


\section{Public health approach}

Consideration of supervisory neglect suggests that there is no "one size fits all" definition. The National Framework for Protecting Australia's Children (COAG, 2009) calls for a public health approach to child protection. In such an approach responses to child protection issues are delivered across three "tiers". In the primary intervention level, the general population is targeted. Legislation prescribing an age limit under which no child can be left unsupervised would be such an intervention. At the secondary level of intervention, families identified as at risk of neglect are targeted and receive specific support to minimise the likelihood of maltreatment. Child care subsidies to families unable to afford after-school care are an example of secondary support. Tertiary interventions rely on the statutory child protection units in each state and territory to intervene in cases where significant harm is suspected and focus primarily on substantiation of maltreatment and then appropriate intervention. These families receive very targeted specific support to enable them to change their behaviours or remove children until they can be considered as safe as possible in their home environment.

The adoption of this framework means that supporting parents and caregivers to adopt behaviours that ensure adequate supervision at all times becomes "everyone's business". Researchers are compelled to identify risk factors associated with injury and at risk populations and disseminate information to injury prevention practitioners and policy-makers so that program can be designed and policies implemented that apply new research knowledge. Government agencies must provide support for high-risk families to enable them to make responsible decisions and keep their children safe. This may be in the form of financial support or providing facilities for occasional out of hours care, for example. Doctors and the health care sector should proactively take responsibility for educating parents and caregivers about developmental stages for children and changing patterns of risk, alerting parents to likely new risks as children grow. Teachers and child care settings should adopt best-practice principles for injury prevention and share knowledge with parents and children that, while modelled at school or in the child care setting, can also be implemented at home. Ideally, community members are involved and ensure their behaviours do not increase risk to children through adopting proven preventive methods like adhering to speed limits and installing pool fences for instance.

\section{Conclusion}

Supervisory neglect is not a new concept but it is hard to define and changing societal norms mean that the definition also changes. However, new work exploring supervision and its role in ensuring the safety of children has allowed for a fresh examination of supervision and its relationship to neglect. The need to forecast where future harm may arise from lack of appropriate supervision and protect children from this harm is paramount.

Consideration must be given to whether or not a specific definition of supervisory neglect is useful from a practice perspective. Definitions are important for identification of cases for inclusion in research and measurement purposes but are less likely to be well served in a practical sense. In a child protection context, children who suffer a number of injuries, albeit minor in terms of severity, may serve as a warning that there are other issues of a potentially neglectful nature, underlying these injuries. A more in-depth analysis of the injury events may reveal patterns of parental behaviour that require support in terms of education about childhood capabilities, additional resources for childcare or support in terms of caregiver capability.

In an assessment of child maltreatment, child protection practitioners should consider children with multiple accidental injuries to be at high risk of neglect, particularly supervisory neglect, and not be too quick to classify a child as "accident prone" without carefully considering the role of supervision 
in those injuries. Parents and caregivers may simply need education about risk of injury and referral to resources for that education rather than intervention at the tertiary level. Organisations such as Kidsafe Australia have injury prevention programs and websites containing information that can educate parents about the risk of injury and the importance of supervision in conjunction with proven environmental measures to reduce childhood injury. This early intervention strategy may then prevent some children from entering into the child protection system.

\section{Resources}

\section{Kidsafe - The Child Accident Prevention Foundation of Australia $<$ www.kidsafe.com.au/>}

Kidsafe is a non-government organisation dedicated to preventing unintentional childhood injuries and reducing the resulting deaths and disabilities associated with injuries in children under the age of 15 years.

\section{References}

Australian Institute of Health and Welfare. (2009). A picture of Australia's children.. Canberra: AIHW.

Australian Institute of Health and Welfare. (2012). Child protection Australia 2010-11 (Child Welfare Series No. 41). Canberra: AIHW.

Bromfield, L., Gillingham, P., \& Higgins, D. (2007). Cumulative harm and chronic child maltreatment. Developing Practice, 19, $34-42$.

Bromfield, L., \& Holzer, P. (2008). A national approach for child protection: Project report. Melbourne: Australian Institute of Family Studies.

Budd, K. (2001). Assessing parenting competence in child protection cases: A clinical practice model. Clinical Child and Family Psychology Review, 4(1), 1-18.

Budeja, L., \& Franklin, R. (in press). An analysis of strategems to reduce drowning deaths of young children in private swimming pools and spas in Victoria, Australia.

Dubowitz, H. (1994). Neglecting the neglect of neglect. Journal of Interpersonal Violence, 9, 556-560.

Dubowitz, H., Black, M., Swan, R., Jr., \& Zuravin, S. (1993). A Conceptual Definition of Child Neglect. Criminal Justice and Behavior, 20, 8-26.

Council of Australian Governments. (2009). Protecting children is everybody's business: A national framework for protecting Australia's children. Canberra: FaHCSIA.

Higgins, D. (1998). Multi-type maltreatment: Relationships between familial characteristics, maltreatment and adjust of children and adults. Doctor of Philosophy, Deakin University, Burwood.

Higgins, D. (2004). Differentiating between child maltreatment experiences. Family Matters, 69, 50-55.

Higgins, D., \& Katz, I. (2008). Enhancing service systems for protecting children: Promoting child wellbeing and child protection reform in Australia. Family Matters, 80, 43-50.

Holzer, P., \& Bromfield, L. (2010). Australian legal definitions: When is a child in need of protection? (NCPC Resource Sheet). Melbourne: Australian Institute of Family Studies.

Hymel, K., \& Committee on Child Abuse and Neglect. (2006). When is lack of supervision neglect? Pediatrics, 118, 1296-1299.

Lamont, A., \& Bromfield, L. (2010). History of child protection services (NCPC Resource Sheet). Melbourne: Australian Institute of Family Studies.

Langley, J. (1986). The need to discontinue the term 'accident' when referring to unintentional injury events. Accident and Analysis, 20(1), 1-8.

Liller, K. (2001). The importance of integrating approaches in child abuse/neglect and unintentional injury prevention efforts: Implications for health educators.. The International Electronic Journal of Health Education, 4, 283-289.

McClure, R., Stevenson, M., \& McEvoy, S. (Eds.). (2004). The scientific basis of injury prevention and control. Melbourne: IP Communications.

Morrongiello, B. A. (2005). Caregiver supervision and child-injury risk: I. Issues in defining and measuring supervison; II. Findings and directions for future research. Journal of Pediatric Psychology, 30(7), 536-552.

Peterson, L., \& Brown, D. (1994). Integrating child injury and abuse-neglect research: Common histories, etiologies and solutions. Psychological Bulletin, 116(2), 293-315.

Queensland Department of Communities. (2011). What is abuse. Retrieved from <www.communities.qld.gov.au/childsafety/ protecting-children/what-is-child-abuse>.

Saluja, G., Brenner, R., Morrongiello, B., Haynie, D., Rivera, M., \& Cheng, T. (2004). The role of supervision in child injury risk: Definition, conceptual and measurement issues. Injury Control \& Safety Promotion., 11(1), 17-22. 
Schnitzer, P., Slusher, P., Kruse, R., \& Tarleton, M. (2011). Identification of ICD codes suggestion of maltreatment. Child Abuse and Neglect, 35(1), 3-17.

Strauss, M. A., \& Kantor, G. K. (2005). Definition and measurement of neglectful behavior: Some principles and guidelines. Child Abuse and Neglect, 29, 19-29.

Towner, E., \& Dowswell, T. (2002). Community-based childhood injury prevention: What works? Health Promotion International, 17, 273-284.

World Health Organization. (1992). ICD-10 Classifications of mental and behavioural disorder: Clinical descriptions and diagnostic guidelines. Geneva: WHO.

Debbie Scott is a Research Fellow and Daryl Higgins is Deputy Director (Research) at the Australian Institute of Family Studies. Richard Franklin is an Associate Professor, School of Public Health, James Cook University.

Acknowledgements: The authors wish to acknowledge the valuable contributions of Jo Clark-Jones, Principle Research Officer, Strategic Policy and Performance Branch of the Queensland Department of Community Services and Reyelle McKeever of the Queensland Commission for Children and Young People and Child Guardian.

\section{Australian Government}

Australian Institute of Family Studies

Child Family Community Australia

(C) Commonwealth of Australia 2012 With the exception of AIFS branding, the Commonwealth Coat of Arms, content provided by third parties, and any material protected by a trademark all textual material presented in this publication is provided under a Creative Commons Attribution 3.0 Australia licence (CC BY 3.0) <creativecommons. org/licenses/by/3.0/au>. You may copy, distribute and build upon this work for commercial and non-commercial purposes; however, you must attribute the Commonwealth of Australia as the copyright holder of the work. Content that is copyrighted by a third party is subject to the licensing arrangements of the original owner.
The Child Family Community Australia (CFCA) information exchange is an information and advisory unit based at the Australian Institute of Family Studies, and funded by the Australian Government Department of Families, Housing, Community Services and Indigenous Affairs. The CFCA information exchange collects, produces and distributes resources and engages in information exchange activities that help to protect children, support families and strengthen communities.

The Australian Institute of Family Studies is committed to the creation and dissemination of research-based information on family functioning and wellbeing. Views expressed in its publications are those of individual authors and may not reflect those of the Australian Institute of Family Studies or the Australian Government Australian Institute of Family Studies

Level 20, 485 La Trobe Street

Melbourne VIC 3000 Australia

Phone: (03) 92147888 Fax: (03) 92147839

Internet: <www.aifs.gov.au>

ISSN 2200-4106

ISBN 978-1-922038-04-3 (cc) BY 